\title{
İşyeri Zorbalığına Çatışma Perspektifinden Bakışın Doğrusal ve Bulanık Mantık Yöntemleriyle Değerlendirilmesi ${ }^{1}$
}

\author{
ESTa ERENLER TEKMEN \\ Sorumlu Yazar, Çankırı Karatekin Üniversitesi ,IIBBF, İşletme Bölümü, \\ esraerenler@karatekin.edu.tr, ORCID:_0000-0002-2509-3149 \\ Ela ÖZKAN CANBOLAT \\ Çankırı Karatekin Üniversitesi İ̈BF İşletme Bölümü, \\ elaozkan@karatekin.edu.tr, ORCID:_0000-0001-7786-3486 \\ Fatma $\boldsymbol{S A} \breve{G} \boldsymbol{L A M}$ \\ fatmakaya898@gmail.com,ORCID:_0000-0001-6455-5142
}

\begin{abstract}
$\ddot{\mathbf{O} z}$
$\mathrm{Bu}$ çalışmanın amacı, iş hayatında sıklıkla yaşanan çatışmaların iş yeri zorbalığı üzerinde etkili olup olmadığını araştırmaktır. Çalışma kapsamında geliştirilen hipotezler, Çankırı Emniyet Müdürlüğü çalışanlarından oluşan örneklemden toplanan verilerle test edilmiştir. Örgütlerde yaşanan çatışmalar, görev ve ilişki çatışması olmak üzere iki boyutta ele alınmıştır. Çatışmanın iş yeri zorbalığı üzerindeki etkisini test etmek için çoklu regresyon analizi yapılmıştır. Ayrıca, değişkenler arasındaki ilişkiler bulanık mantık niteliksel karşılaştırma analizi (fsQCA) yolu ile de değerlendirilerek iki metot sonuçları karşılaştırılmıştır. Çoklu regresyon analizi sonuçları, görev ve ilişki çatışmasının iş yeri zorbalığına maruz kalma davranışı üzerinde anlamlı ve doğru yönlü etkisinin olduğunu gösterirken, fsQCA sadece ilişki kaynaklı çatışmanın iş yeri zorbalığı üzerinde etkili olduğunu göstermiştir.
\end{abstract}

Anahtar Kelimeler: Çatışma, İşyeri Zorbalığı, Bulanık Mantık Niteliksel Karşılaştırmalı Analizi (fsQCA)

JEL Kodları: D23, M10, M12

Evaluation of Analyzing Workplace Bullying from Conflict Perspective by Linear and Fuzzy Logic Methods ${ }^{2}$

\section{Abstract}

The purpose of this study is to investigate whether conflicts frequently experienced in business life have an impact on workplace bullying. The hypotheses developed within the scope of the study were tested with the data collected from the sample of Çankırı Police Department employees. Conflicts in organizations are handled in two dimensions: task and relationship conflict. Multiple regression analysis was performed to test the effect of conflict on workplace bullying. In addition, the relationships between the variables were evaluated through fuzzy logic qualitative comparison analysis (fsQCA) and the results of the two methods were compared. While multiple regression analysis results show that task and relationship conflict has a significant and correct directional effect on workplace bullying exposure, fsQCA has shown that relationship-related conflict is effective only on workplace bullying.

Key words: Conflict, Workplace Bullying, Fuzzy Logic Qualitative Comparison Analysis (fsQCA)

JEL Classification Codes : D23, M10, M12

\footnotetext{
${ }^{1} \mathrm{Bu}$ çalışma, Fatma Sağlam'ın Çankırı Karatekin Üniversitesi, Sosyal Bilimler Enstitisü, İşletme Anabilim Dalı'nda Esra Erenler Tekmen danışmanlığında 2018 yılında tamamlamış olduğu yüksek lisans tezinden türetilmiştir. Çalışmanın tezden farkı, teorik çerçevenin güncellenmesi yanında, analizlerde farklı bir yönteme de başvurulup karşılaştırmaya gidilmesidir.

${ }^{2}$ Extended abstract is presented at the end of the article.

Geliş Tarihi (Received): 18.04.2020 - Kabul Edilme Tarihi (Accepted): 26.06.2020
}

Atıfta bulunmak için/Cite this paper:

Erenler Tekmen, E. Özkan Canbolat, E. ve Sağlam, F. (2020) İşyeri zorbalığına çatışma perspektifinden bakışın doğrusal ve bulanık mantık yöntemleriyle değerlendirilmesi. Çankırı Karatekin Üniversitesi İIBF Dergisi, 10 (1), 349-370. Doi: ckuiibfd.722779 


\section{Giriş}

İki ya da daha fazla kişi arasında yaşanan uyuşmazlıkları ifade eden kişiler arası çatışmalar örgütsel yaşamın kaçınılmaz bir parçasıdır. Çatışmalar etkileşimlerle şekillenir. Çatışmaya neden olan etkileşimler bazen bir anda ortaya çıkarken bazen de zamana yayılan bir dizi davranış, eylem ve tepkiler şeklinde kendini gösterir (Akkoyun, 2013, s. 4). Bu durum işyerlerini bireylerin saldırgan davranışlarla karşılaştıkları, istismar edildikleri veya savunmasız kaldıkları ortamlar haline dönüştürebilir (Matthiesen ve Einarsen, 2004).

Sözlü taciz, tehdit ya da misilleme gibi davranışlar bir çok örgütte yaşanmakta ve çalıșan raporlarına göre iş yerinde deneyimlenen psikolojik travmaların çoğunu üretmektedirler (Aquino, 2000). Bu bağlamda iş yerinde istenmeyen davranışlarla ilgili literatürün gittikçe büyüdüğü de dikkat çekmektedir. İncelemeler, zararlı iş yeri davranışları üzerine yapılan araştırmaların çoğunun faillerin motivasyonları ve özellikleri üzerine odaklandığını göstermektedir. Buna karşın mağduriyet teorileri, insanların diğerlerinin saldırgan eylemlerinin hedefi haline gelmesinin nedenlerini açılayabilmek için faillerin özellikleri dişındaki faktörlerin de dikkate alınması gerektiğinden bahsetmektedir (Aquino, 2000).

Mağdurun kişiliğine ve benlik saygısına tehdit oluşturan (Agervold, 2009), çaresiz konuma getiren, mağdurun nerdeyse her gün ve aylarca süren dönemlerde, bir yada birkaç kişinin saldırısına maruz kaldığı, sosyal bir etkileşimi yansıtan (Leon Perez, Medina, Arenas ve Munduate, 2015) iş yeri zorbalığ 1 karmaşık bir konudur. Pek çok farklı şekilde ortaya çıkabilir, farklı düzeylerde görülebilir ve farklı nedenleri vardır (Agervold, 2009). Keashley ve Nowell (2011) çatışma perspektifinin son derece yıkıcı olan zorbalık olgusunu anlamak ve iyileştirmek noktasında önemli olduğunu belirtmektedir. Zapf ve Gross'a göre (2001) iş yeri zorbalığı, çözülmemiş sosyal bir çatışmayı ifade eder. Çatışmaların örgütler üzerindeki etkileri, çalışanları psikolojik olarak olumsuz etkileme potansiyeli ve bunun sonucunda çalışanların bir takım sorunlar yaşamasına neden olduğu (De Dreu ve Beersma, 2005) hatta iş yerinde zorba davranışları teşvik edebileceği bilinmektedir. Bu perspektiften zorbalık, zamanla tırmanan (Baillien, Notelaers, De Witte ve Matthiesen, 2010) ve çözüme kavuşturulmamış bir çatışma şekli olarak görülebilir (Leon-Perez vd., 2015).

$\mathrm{Bu}$ çalışma, görev ve ilişki çatışması kaynaklı kişiler arası çatışmaların iş yeri zorbalığı davranışı üzerinde etkili olup olmadığını araştırmaktadır. Çalışmada, söz konusu etkiler hem doğrusal modelleme yolu ile hem de bulanık mantık modeli ile değerlendirilmiş ve sonuçlar karşılaştırılmıştır. 


\section{Literatür Taraması}

\section{1. Çatışma}

İş yaşamının bir gerçeği olan çatışma, "örgüt içerisinde yer alan iki veya daha fazla kişi /grup arasında, kıt kaynakların paylaşılması veya işlevsel yönden bağımlılığı olan işlerde birlikte çalışma gerekliliğinden doğan, yine bu kişi ve gruplar arasındaki amaç, değer, statü ya da algı farklılıklarından kaynaklanan anlaşmazlık ya da uyumsuzluğu" anlatır (Şimşek ve Çelik, 2016, s.248). Rahim (2001), çatışmayı taraflar arasındaki uyuşmazlık ve uyuşmazlık içerinde kendini gösteren interaktif bir süreç olarak ele alır (akt. Chan, Huang ve $\mathrm{Ng}$, 2007). Kişiler arası çatışmalar genellikle uyuşmayan ihtiyaçları, fikirleri, inançları ve hedefleri olan taraflar arasında rekabet ortamı oluştuğunda ortaya çıkar (Gültekin, Bayhan Karapınar, Metin Camgöz ve Ergeneli, 2011).

Kişiler arası çatışma konusu ile ilgilenen araştırmacılar genellikle bu çatışma türünü ilişki ve görev çatışması olmak üzere iki boyutta ele almaktadır (De Dreu ve Weingart, 2003). İlişki çatışması, bireylerin tercihlerinin, kişilik özelliklerinin yada fikirlerinin farklılığından kaynaklanan bir çatışma türüdür (Akün ve Palut, 2013). Bu tarz çatışmalarda grup üyeleri arasında kişilik uyuşmazlığ 1 ve bundan kaynaklanan gerilim vardır. Söz konusu gerilim bireylerin birbirlerine düşmanca davranmasına varan sürtüşmelere neden olabilir ve grup üyelerinin birbirleri ile uğraşmaları yüzünden görevleri ile yeterince ilgilenmemelerine yol açabilir (Ergeneli, 2017, s. 271). Görev çatışması, çalışanların görevlerine dair bakış açısı, fikir ve yaklaşım farklılıklarından kaynaklanan çatışmaları ifade eder. Bu tarz çatışmalar kişisel çekişmelerden ziyade prosedürlerden kaynaklanır (Çetin Gürkan ve Demiralay, 2013). Görev ve ilişki çatışmaları arasındaki yüksek korelasyon bunların birbirini tetiklediğini göstermektedir (Ergeneli, 2017, s. 272). Diğer bir ifade ile işle ilgili konularda çalışanlar arasındaki fikir ayrılıklarının kişisel bir anlaşmazlık olarak algılanması durumunda görev çatışmaları ilişki çatışmasına, benzer şekilde çözülmemiş ilişki çatışmaları da işe yansıyarak zaman içerisinde görev çatışmasına dönüşebilmektedir (Williams, 2011, s. 152). Bir başka ifade ile kişisel, algısal ve işlevsel farklılıklar kişiler arası çatışmaların yaşanmasına neden olabilmekte (Bercovitch, 1983) ya da görev çatışmaları zamanla kişilerarası çatışmalara dönüşebilmektedir (Oktay, 2016).

Çatışmalar, niteliğine ve yönetilme biçimine bağlı olarak işlevsel ve işlevsel olmayan bazı etkilere yol açar (Sarpkaya, 2002). Bu bağlamda iyi yönetilemeyen örgütsel çatışmalar çatışan taraflarda zihinsel ya da bedensel sağlığı olumsuz etkileyen bir durum yaratıp, tarafların birbirini düşman olarak görmesine, saldırgan davranışlarda bulunmasına neden olabilir. Ayrıca morali ve tatmini olumsuz etkileyerek verimliliği düşürebilir (Çağlayan, 2006). 


\section{2. İşyeri Zorbalığ1}

İş yerinde zorbalık konusuna olan ilgi 1980'lerde İskandinavya'da ortaya çıkmıştır. Bununla birlikte Heinz Leymann, işyeri zorbalığının olumsuz bireysel ve örgütsel etkilerinin yönetimi ve önlenmesi için günümüzde tüm dünyada devam eden pratik çalışmaların öncüsü ve başlatıcısı olarak görülür (Vartia Vaananen, 2013, s.1). Örgütlerde doğrudan ve dolaylı çatışma biçimlerini araştırmaya karar veren Heinz Leymann çeşitli örgütlerde yaptığı deneysel çalışmalar yoluyla mobbing olgusu ile tanışmış ve 1986'da "Mobbing: İşyerinde Psikolojik Şiddet" başlıklı bir kitap yayınlamıştır (Einarsen, Hoel, Zapf ve Cooper, 2011, s. 4). İlerleyen yıllarda görünüşte "yeni" çoğunlukla "mobbing” e atfedilen işyeri zorbalığı konusundaki farkındalık artmış ve konu giderek daha fazla araştırmacının ilgisini çekmiştir (Einarsen, Hoel, Zapf ve Cooper, 2003). İşyerinde sistemli bir şekilde sergilenen düşmanca tutumların tümünü içeren zorbalık olgusu İngilizce konuşulan ülkelerde iş yeri zorbalığı (workplace bullying), Fransizca konuşulan ülkelerde taciz (harassment), diğer Avrupa ülkelerinde çoğunlukla mobbing olarak adlandırılmaktadır (Einarsen vd., 2011, s. 4).

Günümüz örgütlerinde giderek daha ciddi bir sorun haline gelen (Naseer, Raja ve Donia, 2016), zorbalık "kişinin belirli bir zaman zarfında, tekrarlı olarak kendini üstlerinin veya iş arkadaşlarının olumsuz eylemlerinin hedefi olarak algıladığı, söz konusu davranışlara karşı kendini savunmakta zorlandığ d durumlara işaret etmektedir (Einarsen, 1999). İşyeri zorbalığı, mağdur olan kişi yada kişilerin kendini değersiz hissettiği, failin sistematik ve olumsuz davranışlarının hedefi haline geldiği bir süreci yansitır (Einarsen vd.,2011). Quine' e göre (2001) işyeri zorbalığı, hedef alına kişinin hem örgüt hem de sivil hayatını olumsuz etkileyen ve sistematik bir saldırıya maruz bırakıldığı bir süreçtir. Bu noktada zorbalığın, bireylerin benlik saygısına ve güven duygusuna gitgide zarar veren, hayatında kalıcı hasarlar bırakabilen küçük düşürücü hareket, tutum ve sözleri kapsayan yönünden bahsedilebilir (Körükçü, Yıldırım ve Kukulu, 2014).

Literatürde, zorbalığın kapsamı diğer bir değişle hangi davranışların zorbalık çatısı altında ele alınabileceği noktasında fikir birliği yoktur. Bununla birlikte zorbalık tanımlarında yansitılan ortak özelliklerden birisi olumsuz tutum ya da davranışların tekrarlanması diğeri ise davranışların belirli bir süre boyunca (en az altı ay) devam etmesidir (Çağlar Kuşçu, 2011).

Zorba davranışlar bireyin işine yönlendirilebildiği gibi kişisel de olabilmektedir (Einarsen ve Mikkelsen, 2003; Naseer vd., 2016). Zorbalık genellikle zorba tarafından hedefin işle ilgili görev ve sorumluluklarını yerine getirmesini zorlaştıran olumsuz herhangi bir eylem, taciz, alay etme, lakap takma, dışlama, rencide etme, asılsız söylentiler yayma gibi davranışlarla kendini gösterir (Einarsen vd., 2003) ve bu yönüyle fiziksel ya da psikolojik eylemleri kapsar (Agervold, 2009). İşyeri zorbalığı, bir astın, bir iş arkadaşının veya bir amirinin 
sistematik olarak kötü muamelesi ile ilgilidir, uzun süre devam ederse, hedefte ciddi sosyal, psikolojik ve psikosomatik sorunlara neden olabilir. Zorbalık birçok araştırmacı ve hedef tarafından işyerinde travmatik bir olay, hatta aşırı bir sosyal stres türü olarak görülmektedir. Böyle bir davranışa maruz kalmak, çalışanlar için iş ile ilgili diğer tüm stres türlerinden daha yıkıcı olabilir (Einarsen vd., 2011, s. 4). Einarsen (1999), yıkıcı ve uyuşmazlıkla ilgili zorbalık olmak üzere en az iki zorbalık türü olduğunu öne sürer. Yıkıcı zorbalık, mağdur, zorbanın davranışına bir şekilde sebep olacak veya haklı çıkaracak kışkırtıcı hiçbir şey yapmadığında ortaya çıkar. Diğer yandan, uyuşmazlıkla ilgili zorbalık, iki veya daha fazla taraf arasındaki anlaşmazlıklardan kaynaklanır. Algılanan bazı zararlara veya yanlış davranışlara misilleme tepkileri içerir. Taraflardan biri anlaşmazlık sırasında "dezavantajlı" hale gelirse, zorbalık mağduru olabilir. Dolayısıyla herhangi bir anlaşmazlık zorbalığı tetikleyebilir (Keashly ve Nowell, 2011, s. 424). Simunaniemi ve Köylü'de (2013) kişilerin birbiriyle anlaşamaması ve çekişme halinin, kişinin doğrudan içerisinde olmamasına rağmen kendisine yansıyan çekişmeli durumların, sosyal kimlikler ve aidiyetlerin zorbalığa yol açabileceğinden bahsederler. Diğer yandan bazı araştırmacılar, işyerinde zorbalığın altında yatan mekanizmaları anlamak için kişiler arası çatışma yaklaşımına odaklanmanın önemli olduğunu belirtmektedir (örn. Baillien, Bollen, Euwema ve De Witte, 2014; Baillien, Neyens, De Witte ve De Cuyper, 2009; Keashly ve Nowell, 2011; León-Pérez, Notelaers, Arenas, Munduate ve Medina, 2014; Van de Vliert, 2010). Benzer şekilde, Arenas ve arkadaşları (2015), zorbalığı, etkilenen taraflar arasında güç dengesizliğinin olduğu, duygusal ve ilişkisel sorunların bulunduğu uzun süreli bir çatışmanın son aşaması olarak kabul ederler. $\mathrm{Bu}$ düşünceden hareketle araştırmacılar, süpervizorların güç temelleri hakkındaki algılarının çatışma (görev ve ilişki çatışmaları) ve iş yeri zorbalığı ilişkisindeki rolünü incelemişlerdir. 211 kişi ile gerçekleştirdikleri araştırma, ilişki çatışmasının görev çatışması ve işyerindeki zorbalık arasındaki ilişkiye aracılık ettiğini ortaya koymuştur. İlgili çalışmaya göre, kişisel güç tabanlarının oluşturulması, görev çatışması ile ilişki çatışması ve buna bağlı olarak işyeri zorbalığı arasındaki bağlantının yoğunluğunu azaltmaktadır. Baillien vd.'de (2015) çatışma ve iş yeri zorbalığ 1 arasındaki ilişkiyi incelemek için Hollanda'da 2029 kişi ile bir çalışma yürütmüşlerdir. Çalışma görev çatışmaları ve ilişki çatışmaları yoluyla zorbalık arasındaki ilişkiyi doğrulaşmıştır. Çatışmaların yanı sıra örgütlerde, kişinin yüksek performans göstermesinden kaynaklanan sorunlar da var olabilir ki, yüksek performans zorbalığa maruz kalanların tipik bir özelliğidir (Cemaloğlu, 2007). Kişisel unsurların yanı sıra yönetim tarzı, rol çatışması (Einarsen vd. 1994), rol belirsizliği, işin niteliği, kişiler arası ilişkiler, çatışma, iş akışındaki düzenlemeler (Çağlar Kuşçu, 2011), zayıf sosyal iklim, yüksek performans beklentisi (Agervold, 2009), sosyal çevre (Zapf, Knorz ve Kulla, 1996), dinsel ve politik tutumlar (Solmuş, 2005) gibi pek çok unsurun iş yeri zorbalığına yol açabildiği bilinmektedir. 
Bazı araştırmacılar (De Dreu, Evers, Beersma, Kluwer ve Nauta, 2001), zorbalığı çatışmanın bir alt kümesi olarak görürler. Ancak diğer bazı araştırmacılara göre (Einarsen, 2000; Keashley ve Nowell, 2003; Baillien vd., 2010) zorbalık ve çatışmayı eş anlamlı tutmak zorbalığın zarar verici yapısını ihmal eder. Literatürde işyerlerinde yaşanan çatışmaların zorbalığı teşvik etme potansiyelinden bahsedilmektedir (Ayoko, Callan ve Hartel, 2003; Baillien vd., 2010). Einarsen, Glaso ve Nielson (2008) zorbalığın yıkıcı bir olgu olduğu ve çatışma ile ilişkili olabileceği konusunda hemfikirdirler. Araştırmacılar aynı zamanda "proaktif" saldırganlığın (maddi ve sosyal faydalara ulaşmak için birilerine saldırmanın), örgütlerde zorbalığın baskın formu olduğunu, reaktif saldırganlığın ise (kişinin kızgınken olumsuz davranışlar sergileme eğilimi) daha nadir görüldüğünü belirtmektedirler.

\subsection{Bulanık Mantık Yöntemi}

Konfigürasyonel düşünce analizleri ve nitel araştırmalarla bir kombinasyon sonucu oluşturulan konfigürasyon, sosyal olguları ve yapıları bütüncül/holistik bakış açısıyla değerlendirme eğilimindedir (Ragin, 2008, s.78). Bulanık küme (fuzzy-set) ve bulanık mantık (fuzzy logic), klasik ikili mantık teorisinin dışında kalan fikirleri, bilgileri işleme yeteneğine sahip olan bir yaklaşımdır. Bu yaklaşım istatiksel belirsizliklere mantıksal çözümlemelerle matematiksel cevaplar verir. Çok ölçütlü karar verme araçlarının kullanıldığı bulanık küme teorisi birden çok çelişkili hedeflerin bulunduğu, alternatiflerin karmaşık, ölçütlerin belirsiz olduğu ortamda karar mekanizmalarında oluşan muğlak durumla başa çıkabilmek için etkili bir yöntemdir (Samaddar, Nargundkar ve Daley, 2006, s.745). Ragin (1987) çalışmasında bulanık küme karşılaştırmalı analizinde tahmine odaklanarak belirli bağımlı değişkenler üzerinde önemli etkiye sahip bağımsız değişkenlerin sınırlanmaması gerektiğine dikkat çeker. Diğer bir ifade ile bağımsız değişkenlerin sınırlanması yerine sonuca ulaşan farklı yolların, asimetrik koşullarının varlığından bahseder. Oluşturulan modeller kesin bir sonuç ifade etmez ancak akıl çerçevesinde muhakeme edilebilecek mantıklı çıkarımlar ortaya koyar. Bu çıkarımlar olasılık olarak değerlendirilir ve matematiksel açıklamalarla kesin sonuçlara ulaşılabilir (Zadeh, Fu, Tanaka, Shimura, 1975, s. 200). Teori odaklandığı nokta olan belirsiz durumlarla (Smithson ve Verkuilen, 2006, s. 4) beraber sonuca giden her yolun göreceli olarak önemini inceleyip eş sonuçluluğun analizini ortaya koyar (Fiss, 2011, s. 17).

İşyerinde zorba davranışlar net bir şekilde ölçülemez. Bu gibi durumlar için, günlük hayatta karşılık buldukları ifadelerin ayrıntılarına odaklanan bulanık küme teorisi, zor ve karmaşık soruların çözümünde mantıksal olasılıklar bütününden yararlanır ve doğruya en yakını seçme konusunda etkili bir yöntem olarak değerlendirilir. $\mathrm{Bu}$ çalışma doğrusal modeller ile yapılan analizlere alternatif olarak bulanık mantık metodunu kullanarak veri setlerini kurma süreci ve nesneler 
arası ilişkilerden çıkarımlar yapma konusunda belirsizliğin üzerine giderek yeni ve farklı derecelendirme kombinasyonları tasarlar.

\section{Araştırma Metodolojisi}

\subsection{Araştırmanın Amacı ve Hipotezleri}

$\mathrm{Bu}$ çalışmada, kişiler arası çatışmanın işyerinde zorba davranışların ortaya çıkmasında etkili olup olmadığı sorunsalı üzerinde durulmuştur. Bu bağlamda çalışmada çatışma ve işyeri zorbalığı ilişkisini belirlerken hem doğrusal modelleme hem de bulanık mantık modeli kullanılmıştır. Mevcut çalışma iki modeli karşılaştırarak literatüre katkı sağlamayı amaçlamaktadır.

Önceki kısımda da değinildiği üzere, literatürde, çatışma ile örgüt ortamında gerçekleşen zorbalık arasındaki ilişki potansiyeline işaret edilmektedir (LeonPerez vd., 2015). Örneğin Leymann'a göre (1993) iş yeri zorbalığg, hedefe yönelmiş, tekrarlanan olumsuz hareketleri içeren, kalıcı çatışmaları yansıtır (akt. Zapf, 1999). Einarsen vd. (2008) zorbalığın çatışma ile ilişkili olabileceği konusunda Leymann'la hemfikirdir. Keashley ve Nowell (2011), çatışma perspektifinin zorbalık olgusunu anlamak ve engellemek noktasinda değerlendirilmesi gerektiğinden bahseder. Diğer yandan Ege (2002) zorbalık sürecinde çatışmaların bir ön koşul olarak görülmesi fikrini sorgular (Gregersen, 2017). Bazı yazarlar (Aquino, 2000, Aquino ve Lamertz, 2004, Zapf ve Gross, 2001) çatışmanın, mağdurların zorbalık deneyimine katkıda bulunacağının altını çizerler. Ayoko ve arkadaşları (2003) yaptıkları çalışmada uzun süren çatışmaların zorba davranışları arttırdığını bulmuştur. Bazı çalışmalarda da, zorbalığa maruz kalanların tırmanan çatışmaları, zorbalığın başlıca nedenlerinden birisi olarak algıladıkları görülmektedir (Baillien vd., 2010). Ayrıca, görev kaynaklı çatışmalar ve çalışanlar arasındaki ilişkilerin zayıf olması zorba davranışlar sergilenmesine ortam hazırlayabilmektedir (Simunaniemi ve Köylü, 2013). Ancak çatışma ve zorbalık arasındaki bağlantı halen belirsizliğini korumaktadır (Keashly ve Nowell, 2011, s. 424) ve iki kavram arasındaki ilişkinin incelenmesi noktasında az sayıda çalışma bulunmaktadır. Bahsedilenler 1şı̆̆ında, kişiler arası çatışmanın işyeri zorbalığı ile ilişkili olduğu düşünülerek aşağıdaki hipotez ve alt hipotezler oluşturulmuştur.

\section{H1: Çatışma, iş yeri zorbalı̆̆ına maruz kalma davranışını anlamlı ve doğru yönde etkilemektedir.}

$\mathbf{H 1}_{\mathbf{a}}$ : Görev kaynaklı kişiler arası çatışmalar, iş yeri zorbalığına maruz kalma davranışını anlamlı ve doğru yönde etkilemektedir.

H1 $1_{\mathbf{b}}$ : İliş̧ki kaynaklı kişiler arası çatışmalar, iş yeri zorbalığına maruz kalma davranışını anlamlı ve doğru yönde etkilemektedir. 


\section{2. Örneklem ve Kullanılan Ölçekler}

Çalışmanın ana kitlesini, Çankırı Emniyet Müdürlüğü personeli oluşturmaktadır. Farklı sebeplerle ana kitlenin tamamına ulaşılması mümkün olmadığından örnekleme yoluna gidilmiştir. $\mathrm{Bu}$ çerçevede kolayda örneklem tekniğine başvurulmuş ve 180 kişiden cevap alınabilmiştir. 8 anket güvenilir bulunmadığından analizlere dâhil edilmemiş, analizler 172 anket üzerinden gerçekleştirilmiştir.

Çalışmada 5'li Likert tarzında hazırlanan iki farklı ölçekten yararlanılmıştır. İş yeri zorbalığı, Einarsen ve Raknes (1997) tarafından geliştirilen, sonrasında Einarsen, Hoel ve Notelaers (2009) tarafindan revize edilen, 22 ifadeden oluşan "Olumsuz Davranışlar Ölçeği” ile değerlendirilmiștir. Kișiler Arası Çatıșma Ölçeği ise, 9 maddeden ve iki boyuttan oluşmaktadır (Friedman, Tidd, Currall ve Tsai, 2000). Ölçeklerin uygunluğunun değerlendirilmesi amacıyla esas uygulamaya geçilmeden önce, çalışmanın ön testi 35 kişi ile gerçekleştirilmiş, ifadelerde değişiklik yapılmasına ihtiyaç duyulmamış ardından esas uygulamaya geçilmiştir.

Güvenirlik analizleri çerçevesinde, her bir ölçeğin ve ayrı ayrı her bir ifadenin Cronbach Alfa Değerleri, ayrıca madde çıkarıldığında alfa değerleri hesaplanmıştır. Analiz sonuçlarına göre iş yeri zorbalığı ölçeğinin Cronbach Alfa Katsayıs1 0.888 , kişiler arası çatışma ölçeğininki ise 0.867 olarak bulunmuştur. Sonuçların yazında önerilen, kabul edilebilir düzey olan 0,60 'ın üzerinde olduğu görülmüştür (Hair, 2006, s.137). Çalışmanın verileri oluşturulurken işyeri zorbalığı (22 madde), görev çatışması (4 madde), ilişki çatışması (5 madde) ile ilgili soruların kendi içinde kümülatif toplamları alınmıştır. Ayrıca ankette yer alan ifadelerin normal dağılım gösterip göstermediğini belirlemek için çarpıklık ve basıklık değerlerine bakılmıștır. Çarpıklık değerlerinin +2 ve -2 değerleri arasında olduğu ve normal dağılım gösterdiği gözlenmiştir.

\subsection{Doğrusal Model}

Araştırmanın birinci kısmını oluşturan doğrusal analiz, birden fazla bağımsız değişken olduğu için "çok değişsenli regresyon analizi" olarak belirlenmiştir. Çatışma algısının her bir boyutu (ilişki çatışması ve görev çatışması) araştırmanın bağımsız, motivasyon ise bağımlı değişkenidir.

\subsection{Konfigürasyonlar (koşul değişkenleri), sonuç değişkenleri ve kalibrasyon}

Araşıırmanın ikinci kısmı, çalışanların iş yerinde karşılaştıkları zorba davranışlara yönelik algıları ve çatışma durumları arasındaki ilişkisinin nitel bir yöntem olan Bulanık-set Karşılaştırmalı Niteliksel Analizi (Fuzzy-set Qualitative Comparative Analysis/fsQCA) ile incelenmesini kapsamaktadır. Bu nedenle, yöntem gereği öncelikle çalışanların işyeri zorbalığı ve çatışma algısı konfigürasyonlarının 
belirlenmesi gerekir. Çalışmanın ikinci kısmını oluşturan bu yöntem için işyeri zorbalığı (22 madde), görev çatışması (4 madde), ilişki çatışması (5 madde) ile ilgili soruların kümülatif toplamları konfigürasyonlar olarak belirlenmiştir. Teorik bir yaklaşım aracı olarak QCA Tekniği, konfigürasyon teorilerini test etmeye uygun farklı niteliksel özelliklere sahip kümelerin bulunduğu vakaları inceler ve belirli sonuçları meydana getiren basitleştirilmiş ifadeler elde etmek için "Boole Cebiri” (Boolean Algebra) kullanır (Fiss, 2007). Doğrusallık varsayımı ile örtüşen regresyon ve korelasyon metodunun aksine QCA, eşsonluluk ve değişkenlerin bir arada olmasını dikkate alır. QCA, bir sistemin farklı başlangıç koşulları ve birtakım farklı (ya da çoklu) yollardan aynı nihai duruma ulaşabilmesini sağlayan senaryolara işaret eder (Katz ve Kahn, 1978).

QCA, örgütsel konfigürasyonları karşılaştırmak için bir çerçeve sunarken etkileşimleri sebep/ koşullar (conditions) ve sonuç (outcomes) olarak ilişkilendirir. (Fiss, 2007). Bu çalışma, Fiss'in (2007) önerilerini takip ederek, etkileşim etkileri ve sapma puanları gibi farklı analitik metotlardan sakınmaktadır. Karmaşı nedensellik ve doğrusal olmayan ilişkiler talep ederken QCA metodunun varsayımlarını izlemektedir (Ragin 2008). Araştırmada, çalışanların görev ve ilişki çatışması algısı ile ilgili konfigürasyonların iş yerinde karşılaşılan zorba davranışlar üzerinde etkisinin olabileceği düşünülmüş ve çalışanların işyerinde karşılaştıkları zorbalık algısı ile çatışma algısının birbirleriyle-ilişkili etkileşimi incelenmiştir.

QCA tekniğinin de kullanıldığı bu çalışmada çatışma algısı konfigürasyonları, (görev çatışması ve ilişki çatışması) sebep/koşul olarak belirlenmiştir. Çalışanların işyerinde zorba davranışlara yönelik algıları ise sonuç değişkeni olarak tanımlanmıştır. Koşullar ve sonuçlar için değişkenler (soruların kümülatif değerleri alınarak) elde edildikten sonra, QCA'da kullanılmak üzere kalibre edilmiştir. Kalibre etme kısmı QCA'in niteliksel metot kısmını oluşturmaktadır. $\mathrm{Bu}$ kısımda araştırmacılar koşullar ve sonuç için çapraz eşik değeri (cross-over threshold value), minimum ve maksimum değerler belirlemektedirler. Bu değerler tamamen araştırmanın teorik altyapısı ve araştırmanın yapıldığ örneklem göz önünde bulundurularak araştırmacıların inisiyatifine ve önceliklerine birakılmaktadır (Fiss, 2007; Ragin, 2006; Schneider ve Wagemann, 2010).

Görev çatışma değişkenini kalibre ederken 10 değeri çapraz eşik değeri olarak değeri seçilmiştir. $\mathrm{Bu}$ değer ortalama değerdir. Görev çatışma algısının konfigürasyonlarına ait en büyük ve en küçük değerler; sırası ile 20 ve 4 maksimum ve minimum değerler olarak belirlenmiştir. İlişki çatışma değişkeni kalibre edilirken aynı yol izlenmiş çapraz eşik değeri olarak ortalama değer olan 10 değeri alınmış minimum değer 5 ve maksimum değer 25 alınarak kalibrasyon tamamlanmıştır. Sonuç değişkeni olarak belirlenen iş yeri zorbalığı algısı kalibre edilirken ortalama değer olan 34 çapraz eşik değeri olarak alınırken minimum değer 22 ve maksimum değer 54 alınmıştır. 


\section{Bulgular}

\subsection{Doğrusal Modelleme Yöntemi}

$\mathrm{Bu}$ kısımda bağımlı değişken (işyeri zorbalığı) üzerinde bağımsız değişkenlerin (ilişki ve görev çatışmaları) etkisini anlamak için çok değişkenli regresyon analizi yapılmıştır. Ayrıca bağımsız değişkenler arasında çoklu doğrusal bağlantı (multicollinearity) olup olmama durumu değerlendirilmiştir.

Tablo 1'de görülebileceği gibi korelasyon değerlerinin 0,70 'den küçük olduğu bulunmuş ve doğrusal bağlantı sorununu olmadığı görülmüştür.

Tablo 1. Görev ve İlişski Kaynaklı Çatışmanın İş Yeri Zorbalığına Maruz Kalma Davranışı Üzerindeki Etkisine İlişkin Korelasyon Analizi Sonuçları

\begin{tabular}{|l|c|c|c|c|}
\hline & & $\begin{array}{c}\text { İşyeri } \\
\text { Zorbalığı }\end{array}$ & $\begin{array}{c}\text { Görev } \\
\text { Çatışması }\end{array}$ & $\begin{array}{c}\text { İlişki } \\
\text { Çatışması }\end{array}$ \\
\hline \multirow{2}{*}{$\begin{array}{l}\text { Pearson } \\
\text { Korelasyon }\end{array}$} & İşyeri Zorbalığı & 1,000 & 0,397 & 0,544 \\
& Görev Çatışması & 0,397 & 1,000 & 0,509 \\
\cline { 2 - 5 } & İlişki Çatışması & 0,544 & 0,509 & 1,000 \\
\hline
\end{tabular}

Yapılan analizler sonucunda görev ve ilişki çatışması kaynaklı kişiler arası çatışmanın iş yeri zorbalığına maruz kalma davranışı üzerindeki etkisine ilişkin düzeltilmiş $\mathrm{R}^{2}=, 307$ bulunmuştur. Görev ve ilişki kaynaklı çatışma iş yeri zorbalığı algısının \%31'ini açıklamaktadır. ANOVA analizi (Tablo 2) bağımlı değişkenlerimizden an az birinin bağımlı değişken üzerinde anlamlı bir etkisi olduğunu göstermektedir $(\mathrm{p}=0,000)$.

Tablo 2: Görev ve İlişki Çatışmasıı Kaynaklı Çatışmanın İş Yeri Zorbalığına Maruz Kalma Davranışı Üzerindeki Etkisine İlişkin Sonuçlar

\begin{tabular}{|l|l|l|}
\hline ANOVA & F & Sig. \\
\hline Regresyon & 38,881 &, $000^{\mathrm{b}}$ \\
\hline
\end{tabular}

a. Bağımlı değişken: İşyeri Zorbalığı

b. Belirleyiciler: (Sabit), İlişki Çatışması, Görev Çatışması

Hangi bağımsız değişkenin işyeri zorbalığı üzerinde anlamlı etkisi olduğunu anlamak için yapılan katsayılar (coefficients) analizi Tablo 3'te görülmektedir. 
Sonuçlar, hem görev hem de ilişki kaynaklı kişiler arası çatışmanın iş yeri zorbalığına maruz kalma davranışı üzerinde bir etkisi olduğunu doğrusal modeller yolu ile açıklamaktadır.

Tablo 3:Görev ve İlişki Kaynaklı Çatışmanın İş Yeri Zorbalığına Maruz Kalma Davranışı Üzerindeki Etkisine İlişkin Sonuçlar

\begin{tabular}{|l|c|c|c|}
\hline Coefficients & B & T test & Sig \\
\hline Sabit & 20,578 & 9,969 & $<0.0001$ \\
\hline Görev Çatışması & 0,498 & 2.195 &, 030 \\
\hline İlişki Çatışması & 0,831 & 6,232 & $<0.0001$ \\
\hline
\end{tabular}

\subsection{Bulanık-Set Karşılaştırmalı Niteliksel Analizi}

fsQCA'nın temelinde Doğruluk Tablosu Analizi (Truth Table Analysis) bulunmaktadır. Bu analiz, sonuç için yeterli (sufficient) nedensel kombinasyonları belirler. Doğruluk tablosu analizi tüm olası koşulların kombinasyonlarını listeler (Schneider ve Wagemann, 2010). Bu vakada 2 konfigürasyon olduğu için tüm olası kombinasyon sayısı $2^{2}$ dir. Çalışmada tutarlılık eşiği (consistency threshold), Fiss, 2011; Rihoux ve Ragin, 2009; Schneider ve Wagemann, 2010 tarafindan sağlam sonuçlar oluşturması beklenen bir değer olduğu ifade edilen 0,8 olarak belirlenmiştir. Analiz yalnızca sıfırın üzerinde vakaya ait çözümleri rapor etmektedir (Tablo 4).

Tablo 4: İşyeri Zorbalığı ve Çatışma Algısı Etkileşimi Doğruluk Tablosu Analizi

\begin{tabular}{|c|c|c|c|c|c|}
\hline $\begin{array}{c}\text { Görev } \\
\text { Çatışması }\end{array}$ & $\begin{array}{c}\text { İlişki } \\
\text { Çatışması }\end{array}$ & $\begin{array}{c}\text { İşyeri } \\
\text { Zorbalığı }\end{array}$ & $\begin{array}{c}\text { Sıra } \\
\text { tutarlılı̆̆ }\end{array}$ & $\begin{array}{c}\text { PRI } \\
\text { tut. }\end{array}$ & $\begin{array}{c}\text { SYM } \\
\text { tut. }\end{array}$ \\
\hline 0 & 1 & 1 & 0,883 & 0,612 & 0,614 \\
\hline 1 & 1 & 1 & 0,860 & 0,648 & 0,691 \\
\hline 1 & 0 & 0 & 0,742 & 0,348 & 0,358 \\
\hline 0 & 0 & 0 & 0,606 & 0,225 & 0,232 \\
\hline
\end{tabular}




\subsection{1. İşyerinde karşılaşılan zorba davranışlar için çözüm terimi önerileri}

fsQCA, varsayımların basitleştirilmesine bakılmaksızın karmaşık ve hassas çözümleri hesaplarken, orta yollu çözüm varsayımların basitleştirilmesi özelliklerine bağlıdır. Varsayımları sadeleştirme/ basitleştirme göz önünde bulundurulduğunda, orta yollu çözüm fsQCA sonuçlarını yorumlamak için ana referans noktası olarak önerilir. Ragin (2006) çalışmalarda ampirik önemin değerlendirmesi için ham/hasas kapsam (raw coverage) ve benzersiz kapsam (unique coverage) değerleri ile çözüm tutarlılık (toplam tutarlılık) değerlerini kullanmayı önermektedir. Ham / hassas kapsam, nedensel / koşulsal durum setleri ile sonuç setleri arasındaki çakışmaların boyutunu belirlemektedir (Schneider ve Wagemen, 2010). Benzersiz kapsam ise, ham/hassas kapsamı bölümlere ayırarak örtüşen açıklamaları kontrol etmeyi gösterir. İlgili değerler Tablo 5'de gösterilmektedir.

Tablo 5: İşyeri zorbalığı sonuç değişkeni için çözüm terimi

\begin{tabular}{|l|c|c|c|}
\hline Çözüm Terimi & $\begin{array}{l}\text { Kapsam } \\
\text { (ham) }\end{array}$ & $\begin{array}{l}\text { Kapsam } \\
\text { (benzersiz) }\end{array}$ & Tutarlılık \\
\hline İlişki çatışması & 0,686 & 0,686 & 0,825 \\
\hline Tüm Çözüm & 0,686 & & 0,825 \\
\hline
\end{tabular}

Tüm nedensel yolların önemi olarak ifade edilen toplam kapsam (total coverage) bu araştırmada 0,686 olarak hesaplanmıştır. Bu sonuç, nedensel yolun, sonucun çoğunu kapsadığını açıklar. Tek nedensel/koşulsal yolların ham/hassas kapsamı ise ilişki çatışması sonuç yolu için yine 0.686 'dir. Bu yol için benzersiz kapsam 0,686 'dir.

Tablo 5 sadece bir çözümün (ilişki çatışması konfigürasyonunun) iş yeri zorbalığ 1 ile olan ilişkiyi açıklayabileceğini göstermektedir. Diğer bir ifade ile ilişki çatışması kaynaklı kişiler arası çatışmanın iş yeri zorbalığına maruz kalma davranışı üzerindeki etkisi bulanık mantık metodu ile kanıtlanırken, görev çatışmasının iş yeri zorbalığı üzerindeki etkisi kanıtlanmamıştır.

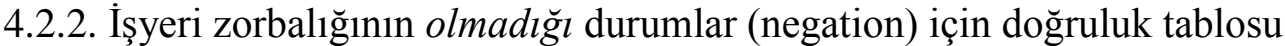

Bir sonucun eksikliği-negation çoğunlukla belirlenecek hipotezlerin bir parçası değilse de önerilen bir yoldur (Ragin, 2006). Olumsuzluk vakalarının analizi, olumlu davaları yönlendiren nedensel mantığın anlaşılmasına yardımcı olabilir ve/veya kendi başına önemli derecede ilginç bilgiler üretebilir. İzleyen kısımda, görev ve ilişki çatışması kaynaklı kişiler arası çatışmanın iş yeri zorbalığına 
maruz kalma davranışı üzerindeki etkisinin olmadiğ incelenmiştir.

Tablo 6: İşyeri Zorbalığına Maruz Kalma Durumunun Olmadı̆̆ı Durumlara İlişkin Doğruluk Tablosu

\begin{tabular}{|c|c|c|c|c|c|}
\hline $\begin{array}{c}\text { Görev } \\
\text { Çatışması }\end{array}$ & $\begin{array}{c}\text { İş yeri } \\
\text { çatışması }\end{array}$ & $\begin{array}{c}\text { ¿̇ş yeri } \\
\text { zorbalı̆̆ı }\end{array}$ & $\begin{array}{c}\text { Sıra } \\
\text { tutarlılı̆̆ı }\end{array}$ & $\begin{array}{c}\text { PRI } \\
\text { tut. }\end{array}$ & $\begin{array}{c}\text { SYM } \\
\text { tut. }\end{array}$ \\
\hline 0 & 0 & 1 &, 0870 & 0,745 & 0,768 \\
\hline 1 & 0 & 1 & 0,851 & 0,624 & 0,642 \\
\hline 0 & 1 & 1 & 0,851 & 0,385 & 0,386 \\
\hline 1 & 1 & 0 & 0,718 & 0,290 & 0,309 \\
\hline
\end{tabular}

Tablo 6' daki doğruluk tablosu analizinde tüm olası koşulların kombinasyonları listelenmiştir. Daha öncede belirtildiği üzere mevcut çalışmada tutarlılık eşiği 0,8 olarak belirlenmiştir. Analiz vakaya ait yalnızca sıfırın üzerinde olan çözümleri rapor etmektedir (Fiss, 2011; Rihoux ve Ragin, 2009; Schneider ve Wagemann, 2010).

\subsubsection{Zorbalığın olmadiğ $l$ durumlar (negation) için çözüm terimi önerileri}

QCA zorba davranışların olmadı ̆̆ durumları, işyeri zorbalığının çatışma algısı konfigürasyonlarıyla olan ilgisinin ve etkileşiminin güvenilirliğini kontrol etmek için "kontrol değişkeni" olarak kullanmaktadır. Yapılan analizlerde işyeri zorbalığının olmadığı durumlar için iki çözüm önerisi bulunmuştur (Tablo 7). Bunlardan illişki çatışması için ham/hassas kapsam 0,882 ve benzersiz kapsam sonucu 0,156 , 〜Görev çatışması çözüm terimi için ham/hassas kapsam 0,763 ve benzersiz kapsam sonucu 0,364 bulunmuştur. İlişki ve görev çatışmasının yaşanmadığı durumlarda işyerinde zorba davranışlar da ortaya çıkmamaktadır. Bu iki çözüm yolu da Tablo 5'deki çözüm yolları ile aynı olmadığından işyeri zorbalığı ve çatışma konfigürasyonları etkileşiminde Tablo 5'deki çözüm yolunun kontrolü sağlanmıştır. 
Tablo 7: İşyeri zorbalığının olmadığı (negation) durumlar için çözüm terimi

\begin{tabular}{|l|c|c|c|}
\hline Çözüm Terimi & $\begin{array}{l}\text { Kapsam } \\
\text { (ham) }\end{array}$ & $\begin{array}{l}\text { Kapsam } \\
\text { (benzersiz) }\end{array}$ & Tutarııık \\
\hline 〜ilişsi çatışması & 0,882 & 0,156 & 0,776 \\
\hline Görev çatışması & 0,763 & 0,364 & 0,826 \\
\hline Tüm Çözüm & 0,918 & & 0,750 \\
\hline
\end{tabular}

\section{Sonuç}

$\mathrm{Bu}$ çalışmanın amacı, iş yerinde sergilenen zorba davranışlar üzerinde kişiler arası çatışmaların bir rolünün olup olmadığını ortaya koymaktır. Değişkenler arası ilişkiler değerlendirilirken mağdurun bakış açısını anlayabilmek için kurban/mağdur yaklaşımı benimsenmiştir. Mevcut çalışmada öncül koşulları ve değişkenler arasındaki örüntüleri daha iyi anlamak için doğrusal modellemeye ek olarak alternatif bir metot da kullanılmış ve iki farklı metot sonuçları karşılaştırılmıştır. Yapılan analizler doğrusal modelleme ve bulanık mantık metotlarının farklı sonuçlar ürettiğini göstermiştir.

Bu çalışmada doğrusal modelleme yolu ile yapılan çoklu regresyon analizi hem ilişki hem de görev kaynaklı kişiler arası çatışmanın iş yeri zorbalığına maruz kalma davranışı üzerinde pozitif ve anlamlı bir etkisinin olduğunu göstermiştir. Elde edilen sonuçlar, Arenas vd (2015), Baillien vd. (2015), Ayoko vd. (2003)'nin çalışmalarının sonuçlarıyla tutarlıdır. Bununla birlikte çalışmanın hipotezleri doğrudan model perspektifinden doğrulanırken, bulanık mantık ile yapılan analizler sadece ilişki kaynaklı çatışmanın iş yeri zorbalığı üzerinde etkisinin olduğunu göstermiştir. QCA, ilişki ve görev kaynaklı çatışmaların beraber oluştuğu durumları da incelemektedir (ilişki çatışması*görev çatışması). Bu çalışmada aynı anda hem ilişki hem de görev çatışması yaşanmasının, diğer bir ifade ile iki tür çatışmanın beraber yaşandığı durumların iş yeri zorbalığına maruz kalma davranışına etkisi bulunmamıştır. Kısaca, doğrusal modelleme, hem ilişki hem görev kaynaklı çatışmasının işyerinde zorba davranışlara maruz kalma durumunu etkilediğini gösterirken, bulanık mantık metodu iş yerinde maruz kalınan zorba davranışlar üzerinde sadece ilişki çatışmasının rol oynadığını göstermiştir. Yapılan litetarür taramasında çatışma ve iş yerinde zorba davranışları fsQCA yöntemiyle analiz eden bir çalışmaya rastlanmamıştır. Bu nedenle alanın karşılaştırmalı nitel analiz tekniğiyle yapılacak çalışmaların katkısına açık olduğu söylenebilir. 
Mevcut çalışma, çatışma ve iş yeri zorbalığı arasındaki ilişkiyi ortaya koyarak, iş yeri zorbalığının altında yatan mekanizmayı bir yönüyle açıklamaktadır. Bahsedilenler 1şığında, örgütlerde yaşanan çatışmaların bireylerin kendilerine yönelik davranışları etkileme potansiyeline sahip olduğu, çalışanların örgüt ortamında yaşadıkları çatışmaların gücünün farkında olmasının ve doğru şekilde yönetmesinin önemli olduğu söylenebilir. Konunun derinleştirilmesi, iş yeri zorbalığı olgusunun daha iyi anlaşılabilmesi için sonraki çalışmalarda, hem zorbalık mağdurlarının hem de zorbaların, çatışmaların tırmanmasına yol açan davranışları ve iş yeri zorbalığının örgütsel bağlılık, iş tatmini gibi çeşitli iş tutumları üzerindeki etkileri incelenebilir.

\section{Kaynaklar}

Agervold, M. (2009). The significance of organizational factors fort he incidence of bullying. Scandinavian Journal of Psychology, 50: 267-276.

Akkoyun, F. (2013). Çatışma yönetimi- insan ilişkilerinde, gruplarda ve örgütlerde çatışmayı yönetme stratejileri. Ankara : Nobel yayınları.

Akün Palut, F.A. (2013). İşyerinde algılanan kişilerarası çatışmaların stres belirtileri ile ilişkisinde psikolojik sermaye ve çatışma yönetimi tarzlarının biçimlendirici etkileri, İstanbul Üniversitesi Sosyal Bilimler Enstitüsü, Yüksek Lisans Tezi, İstanbul.

Aquino, K. (2000). Structural and individual determinants of workplace victimization: the effects of hierarchical status and conflict management style, Journal of Management, 26(2): 171-193.

Aquino, K ve Lamertz, K. (2004). A relational model of workplace victimization: social roles and patterns of victimization in dyadic relationship. Journal of Applied Psychology, 89 (6). 1023-1034.

Arenas, A., Leon-Perez, J.M., Munduate, L. Medina, F.J. (2015). Workplace bullying and interpersonal conflicts: the moderation effect of supervisor's power. International Journal of Social Psychology, 30 (1), 1-12.

Ayoko, O., Callan, V. ve Härtel, C. (2003). Workplace conflict, bullying and counterproductive behaviours. International Journal of Organizational Analysis, 11(4), 283-301.

Baillien, E., Camps, J., Van den Broeck, A., Stouten, J., Godderis, L., Sercu, M., \& De Witte, H. (2015). An eye for an eye will make the whole world 
blind: Conflict escalation into workplace bullying and the role of distribute conflict behavior. Journal of Business Ethics, 1(1), 1-15.

Baillien, E., Bollen, K., Euwema, M., \& De Witte, H. (2014). Conflicts and conflict management styles as precursors of workplace bullying: A twowave longitudinal study. European Journal of Work and Organizational Psychology, 23, 511-524.

Baillien, E., Notelaers G., De Witte, H. ve Matthiesen, S.B. (2010). The relationship between the work unit's conflict management styles and bullying at work: moderation by conflict frequency. Economic and Industrial Democracy, 32(3), 401-419.

Baillien, E., Neyens, I., De Witte, H., \& De Cuyper, N. (2009). A qualitative study on the development of workplace bullying: Towards a three way model. Journal of Community and Applied Social Psychology, 19, 1-16.

Bercovitch, J. (1983). Conflict and conflict management in organizations: A framework for Analysis. Hong Kong Journal of Public Administration, 5(2), 104-123.

Cemaloğlu, N. (2007). Örgütlerin kaçınılmaz sorunu: Yıldırma, Bilig, (42): 111126.

Chan, K.W., Huang, X. ve Ng, P.M. (2007). Managers' conflict management styles and employee attitudinal outcomes: The mediating role of trust. Asia Pacific Journal of Management, 25(2), 277-95.

Çağlar Kuşçu, P. (2011). İşyeri zorbalığı ve örgüt kültürü ilişkisi üzerine sosyolojik bir araştırma. Uluslararası Sosyal Araştırmalar Dergisi, 4(19), 371-394.

Çağlayan, O.A. (2006). Örgütsel çatışma yönetimi ve bir araştırma, Pamukkale Üniversitesi Sosyal Bilimler Enstitüsü, Yayımlanmamış yüksek lisans tezi, Denizli.

Çetin Gürkan, G. ve Demiralay, T. (2013). İlişki ve görev çatışması ile işten ayrılma niyeti ilişkisinin araştırılması: Konaklama işletmeleri çalışanları üzerine bir araştırma. Eskişehir Osmangazi Üniversitesi Sosyal Bilimler Dergisi, 14(2), 59-79.

De Dreu, C.K.W., Evers, A., Beersma, B., Kluwer, E.S. ve Nauta, A. (2001). The theory-based measure of conflict management strategies in the workplace. Journal of Organizational Behavior, 22, 645-668. 
De Dreu, C.K.W. ve Weingart, L.R. (2003). Task versus relationship conflict, team performance, and team member satisfaction: A Meta- Analysis. Journal of Applied Psychology, 88(4), 741-749.

De Dreu, C.K.W. ve Beersma, B. (2005). Conflict in organizations: beyond effectiveness and performance. European Journal of Work and Organizational Psychology, 14 (2), 105-117.

Einarsen, S., Raknes, B.I. ve Matthiesen, S.B. (1994). Bullying and harassment at work and their relationships to work environment quality: an exploratory study. European Work and Organızatıonal Psychologist, 4 (4), 381-401.

Einarsen, S. ve Raknes, B. I. (1997). Harassment in the workplace and the victimization of men. Violence and Victims, 12(3), 247-263.

Einersan, S. (1999). The nature and causes of bullying at work. International Journal of Manpower, 20(1/2), 16-27.

Einersan, S. (2000). Harassment and bullyıng at work: A review of the Scandinavian approach. Aggression and Violent Behavior, 5(4), 379-401.

Einarsen, S. ve Mikkelsen, E.G. (2003). Individual effects of exposure to bullying at work. Einarsen, S., Hoel, H., Zapf, D. and Cooper, C.L. (Eds.), Bullying and emotional abuse in the workplace, international perspectives in research and practice, London, UK: Taylor and Francis.

Einarsen, S., Hoel, H., Zapf, D. ve Cooper, C.L. (2003). The concept of bullying at work: The European tradition. S. Einarsen, H. Hoel, D. Zapf ve C.L. Cooper (Eds.), Bullying and emotional abuse in the workplace: International Perspectives in Research and Practice. London: Taylor and Francis.

Einarsen, S., Hoel, H. ve Notelaers, G. (2009). Measuring exposure to bullying and harassment at work: Validity, factor structure and psychometric properties of the Negative Acts Questionnaire-Revised, Work \& Stress, 23 (1), 24-44.

Einarsen, S., Hoel, H., Zapf, D. ve Cooper, C.L. (2011). Bullying and harassment in the workplace, development in theory, research and practice, USA: Taylor \& Francis Group.

Ergeneli, A. (2017). Örgütsel Davranış, Ankara: Nobel Yayınevi

Fiss, P. C. (2007). A set-theoretic approach to organizational configurations. The Academy of Management Review, 32(4), 1180-1198. 
Fiss, P. C. (2011). Building better causal theories: A fuzzy set approach to typologies in organization research. Academy of Management Journal, 54 (2), 393-420.

Friedman, R.,Tidd, S., Currall, S.C. ve Tsai, J. (2000). What goes around comes around: The impact of personal conflict style on work conflict and stres. The International Journal of Conflict Management, 11(1), 32-55.

Gregersen, J. (2017). Is workplace bullying a conflict? Examples from Norwegian lawsuits. Psychiatry, Psychology and Law, 24(3), 428-439.

Gültekin, S., Bayhan Karapınar, P., Metin Camgöz, S. ve Ergeneli, A. (2011). Do stages of moral developmant matter in the preference of conflict handling styles with peers?. International Journal of Humanities and Social Science, 1(7), 223-230.

Hair, J.F., Black, W.C., Babin, B. J., Anderson, R. E., ve Tatham, R. L. (2006). Multivariate data analysis. New Jersey: Prentice Hall

Katz, D., ve Kahn, R. L. (1978). Organizations and the system concept. Classics of organization theory, 161-172.

Keashly, L., \& Nowell, B. (2003). Conflict, conflict resolution and bullying. Einarsen, S., Hoel, H., Zapf, D. ve Cooper, C. (Ed.), Bullying and emotional abuse in the workplace: International research and practice perspectives. London: Taylor \& Francis.

Keashley, L. ve Nowell, B.L. (2011). Workplace bullying, conflict and conflict resolution. In S. Einarsen, H. Hoel, D. Zapf, \& C. L. Cooper (Ed.), Bullying and harassment in the workplace: Developments in theory, research and practice. London: Taylor \& Francis.

Körükcü, Ö., Yıldırım N. ve Kukulu, K. (2014). Hemşirelikte önemli bir sorun: zorbalık (Bullying). Balıkesir Sağlık Bilimleri Dergisi, 3(2), 126-129.

León-Pérez, J. M., Notelaers, G., Arenas, A., Munduate, L., \& Medina, F. J. (2014). Identifying victims of workplace bullying by integrating traditional estimation approaches into a latent class cluster model. Journal of Interpersonal Violence, 29, 1155-1177.

Leon-Perez, J.M., Medina, F.J., Arenas, A. ve Munduate L. (2015). The relationship between interpersonal conflict and workplace bullying, coping with conflict and bullying at work. Journal of Managerial Psychology, $30(3), 1-22$. 
Matthiesen, S.B. ve Einarsen, S. (2004). Psychiatric distress and symptoms of PTSD among victims of bullying at work. British Journal of Guidance \& Counselling, 32 (3), 335-356.

Naseer, S., Raja, U., ve Donia, M.B.L. (2016). Effect of perceived politics and perceived support on bullying and emotional exhaustion: The moderating role of type a personality. The Journal Of Psychology, 150(5), 606-624.

Oktay, F. (2016). Çatışma yönetimi ile örgütsel destek arasındaki ilişkinin incelenmesi. Gaziantep University Journal of Social Sciences, 15(4), 1146-1155.

Ragin, C. C. (1987). The comparative method: Moving beyond qualitative and quantitative strategies [Elektronik Sürüm] Oak 1\& California: University of California Press.

Ragin, C.C. (2006). Set relations in social research: Evaluating their consistency and coverage. doi:10.1093/pan/mpj019 .

Ragin, C. C. (2008). Redesigning social inquiry: Fuzzy sets and beyond (Vol. 240). Chicago: University of Chicago Press.

Rihoux, B., ve Ragin, C.C. (2009). Configurational comparative methods: Qualitative comparative analysis (QCA) and related techniques. Sage Publications.

Samaddar, S., Nargundkar, S., ve Daley, M. (2006). Inter-organizational information sharing: The role of supply network configuration and partner goal congruence. European Journal of Operational Research, 174(2), 744765.

Sarpkaya, R. (2002). Eğitim örgütlerinde çatışma yönetimi ve bir örnek olay. Eğitim Yönetimi Dergisi, 31, 414-429.

Schneider, C.Q., ve Wagemann, C. (2010). Standards of good practice in qualitative comparative analysis (QCA) and fuzzy-sets. Comparative Sociology, 9(3), 397-418.

Simunaniemi, M. ve Köylü, M. (2013). Kaos GL'den işyerinde zorbalık ve mobbing Bilgi Notu, [Erişim: 11 Nisan 2020, http://www.kaosgl.org/sayfa.php?id=15426].

Smithson, M., ve Verkuilen J. (2006). Fuzzy Set Theory. Terry D. Clark, Jennifer M. Larson, John N. Moderson, Joshua D. Portter ve Mark J. Wierman (Ed.). Applying Fuzzy Mathematics to Formal Models in Comparative Politics. (S. 29-63). Thousand Oaks, CA: SAGE Publications lnc. 
Solmuş, T. (2005). İş yaşamında travmalar: cinsel taciz ve duygusal zorbalık/Taciz. İş Güç Endüstri Illişkileri ve Insan Kaynakları Dergisi, 7(2), $1-14$.

Şimşek, M.Ş. ve Çelik, A. (2016). Yönetim ve Organizasyon, 18. Baskı, Konya: Eğitim Yayınevi

Vartia-Vaananen, M. (2013). Workplace bullying and harassment in EU and Finland: in JILPT Seminar on Workplace Bullying and Harassment, Report no: 12, Japan: The Japan Institute for Labor Policy and Training Pub.

Williams, F. (2011). Interpersonal conflict: the importance of clarifying manifest conflict behavior. International Journal of Business, Humanities and Technology, 1(3), 148-152.

Zadeh, L. A., Fu, K., Tanaka, K. ve Shimura, M. (1975). Fuzzy sets and their applications to cognitive and decision processes, New York: Academic Press.

Zapf, D., Knorz, C. ve Kulla, M. (1996). On the relationship between mobbing factors, and job content, social work wnvironment, and health outcomes. European Journal of Work and Organızatıonal Psychology, 5(2), 215-237.

Zapf, D. (1999). Organisational, work group related and personal causes of mobbing/bullying at work. International Journal of Manpower, 20, 1(2), 70-85.

Zapf, D., ve Gross, C. (2001). Conflict escalation and coping with workplace bullying: A replication and extension. European Journal of Work and Organizational Psychology, 10(4), 497-522. 


\title{
Evaluation of Analyzing Workplace Bullying from Conflict Perspective by Linear and Fuzzy Logic Methods
}

\author{
Extended Abstract
}

\section{Introduction}

Conflict, an interactive process that expresses disputes between the parties, is part of organizational life. Conflict describes disputes between two or more people/ groups within an organization, arising from the need to share scarce resources or to work together in jobs that are functionally dependent, and resulting from differences in purpose, value, status or perception between these individuals and groups (Şimşek and Çelik, 2016) and is shaped by interpersonal interactions.

Conflicts can be classified in different ways. In this study, interpersonal conflict is dealt with in two dimensions as relationship and task conflicts (De Dreu and Weingart, 2003). Relationship conflict arises from the difference of individuals' preferences, personality traits or ideas (Akün and Palut, 2013). In such conflicts, personality differences between group members create a tense work environment and cause individuals to behave hostile to each other (Ergeneli, 2017). Task conflict refers to conflicts arising from the differences of perspectives, opinions and approaches about the duties of the employees. This type of conflict usually results from procedures (Çetin Gürkan and Demiralay, 2013). If the differences of opinion among employees on work-related issues are perceived as personal, task conflicts may turn into relationship conflicts, and similarly unresolved relationship conflicts can be reflected on the job and become task conflicts over time (Williams, 2011, p. 152). In addition, conflicts can turn organizations into environments where employees are exposed to undesirable behavior or abuse, and cannot defend themselves (Matthiesen and Einarsen, 2004).

Workplace bullying refers to the persistent target of an employee who is unable to defend himself to the aggressive, hostile and negative behavior of the manager, colleagues or subordinates (Leymann, 1996; Einarsen, Hoel \& Notelears, 2009). "Bullying is social exclusion, harassment, hurt or negatively affecting the way the employees do their jobs". In order to consider an act as bullying, the related behaviors must be repeated systematically and continue for a certain period of time. One-time or occasional negative behavior is not covered under bullying (Einarsen et al. 2003). There are several reasons for workplace bullying. The characteristics of the victim, the characteristics of the bully, the characteristics of the work environment, different interests, conflicts (Işık, 2015), management style, role ambiguity (Einarsen et al. 1994), weak social climate, high-performance expectation (Agervold, 2009) are some of them. Previous studies examining the relationship between conflict and workplace bullying address the importance of focusing on the conflict perspective to understand the mechanisms underlying workplace bullying and to resolve the problem (Baillien et al. 2014; Baillien et al. 2009; Keashly and Nowell, 2011; León-Pérez et al. 2014). This study investigates whether task and relation conflicts are effective in workplace bullying, which is becoming an increasingly serious problem in organizations. The aforementioned effects were examined both with linear modeling and the fuzzy logic model. This study aims to contribute to the literature by comparing the two models.

\section{Methodology}

In this study, the question of whether an interpersonal conflict is effective in the appearance of bully behavior in the workplace is emphasized. The main population of the study is the personnel of the Çankırı Police Department. Since it is not possible to reach the entire population, the 
convenience sampling method was used. The data were collected using a questionnaire, and analyzes were performed on 172 questionnaires. In the study, two different scales which are prepeared in 5 point likert scale. Workplace bullying was evaluated with the "Negative Act Questionnaire" including 22 statements revised by Einarsen, Hoel and Notelaers (2009). The Interpersonal Conflict Scale consists of 9 items and two dimensions (Friedman, Tidd, Currall and Tsai, 2000). Reliability analysis results showed that the Cronbach's alpha values of the scales used were above (0.60) the acceptable level (Hair et al., 2006).

\section{Results and Discussion}

In order to examine the impact of each aspect of interpersonal conflict (relationship conflict and task conflict), "Multivariate regression analysis" was made on workplace bullying in the first phase of the study. Results showed that interpersonal conflict, both task and relationship-based, had a significant and correct directional effect on workplace bullying behavior. Thus, the H1 hypothesis and sub-hypotheses were confirmed by linear modeling. The results obtained are consistent with the results of the works of Arenas et al. (2015), Baillien et al. (2015), Ayoko et al. (2003).

In the second stage of the research, the relationship between the perceptions of employees about bullying behaviors at work and conflict situations was examined with a qualitative method, (Fuzzy-set Qualitative Comparative Analysis). Given the simplification/abbreviation of the hypothesis, the midway solution is recommended as the main reference point for interpreting fsQCA results. Ragin (2006) proposes to use raw/sensitive coverage and unique coverage values and solution consistency (total consistency) for the evaluation of empirical importance. In this study, total coverage was calculated as 0.686 . This result shows that the causal pathway encompasses most of the results. The raw/sensitive scope of the only causal/conditional pathways of the relationship conflict was found to be 0.686 for the result path. The unique coverage for this pathway is 0.686 . The results show that only one solution (relationship conflict configuration) is related to workplace bullying. In other words, the effect of interpersonal conflict on exposure to workplace bullying was confirmed by the fuzzy logic method, whereas the effect of task conflict on workplace bullying was not confirmed. Thus, only the H1b hypothesis was accepted through the fuzzy logic model.

\section{Conclusion}

In the current study, an alternative method was used in addition to linear modeling to better understand the patterns between the antecedents and variables, and the results of the two different methods were compared. The analysis showed that linear modeling and fuzzy logic methods produce different results.

This study reveals the relationship between conflict and workplace bullying and explains it in one aspect to the mechanism underlying workplace bullying. In the light of the aforementioned findings, it can be said that the conflicts in organizations have the potential to affect the behaviors of individuals, and it is important for the employees to be aware of the power of conflicts in the organization environment and to manage them correctly.

In the future studies, behaviours of both of the victims and bullies which causes the escalation of conflicts can be examined to deepen the issue and for better understanding of bullying phenomenon. The effects of workplace bullying on various business attitudes such as organizational commitment and job satisfaction can be examined. Finally, in the literature review, since there is no study analyzing conflict and bullying behaviors in the workplace with the fsQCA method, it can be said that the field is open to the contribution of the studies to be carried out with the comparative qualitative analysis technique. 